\title{
HOW DOES ABUSIVE LEADERSHIP CONTAMINATE PERFORMANCE AND CULTURE? AN EMPIRICAL ANALYSIS
}

\author{
Zainab Fatima Bokhari \\ Research Scholar, Department of LMS, National Defence University \\ zainabbukhari@gmail.com \\ Muhammad Ismail Ramay \\ Associate Professor, National Defence University \\ Dean.ramay@gmail.com \\ Muhammad Zia-ur-Rehman \\ Associate Professor, National Defence University \\ Drziaofficial@gmail.com
}

\begin{abstract}
The study focuses on the critical aspect which is evaluation of how much of an impact does the abusive leadership have on the employees' performance when the hospital culture promotes it, overlooks it, or embraces it. The target sample of 350 was performing multi functions including doctors, nurses, paramedics, and medical staff. For the antecedent of Abusive Leadership, data was collected from 35 hospital supervisors. The study observed nonphysical abuse such as verbal mistreatment, mockery, insulting behavior, emails, and messages. The results show a significant impact of leadership on employee performance and stress that was caused by leadership's negative behavior; organizational culture also was causing stress toward the employees' performance.
\end{abstract}

Keywords: Abusive leadership, commitment, productivity, performance, culture

\section{INTRODUCTION}

The toxic effect of nonphysical abuse by a supervisor is much broader than believed. According to Crystal Farh, (Farh \& K. Oh, 2015), supervisors who belittle and ridicule workers not only negatively affect those workers' attitudes and behaviors but also cause organization members to act in a similar hostile manner towards one another. Abusive leadership refers to employees' perceptions of the extent to which the leader engages in the sustained display of hostile verbal and nonverbal behaviors, excluding physical contact (Tepper, 2000). Many scholars have studied the effects of such harmful roles that abusive supervision played on organizations and staffs from multiple perspectives. Firstly, from the individual perspective, existing research has shown that abusive supervision plays a significantly negative effect on employees' work and life, causing emotional exhaustion, decreasing the sense of psychological security (Marilyn, Whitman, Halbesleben, \& Oscar, 2012), reducing job satisfaction (Yukl, 2002), job performance (Hoobler, \& Brass, 2006) and employee creativity (Dong, Hui, \& Raymond, 2012), increasing turnover intention (Surienty, Chiun, \& Natasha, 2014), and even causing counter productive work behavior (Tepper, 2008)

Abusive leadership creates a context where everybody suffers regardless of whether one was abused individually or not. This study focuses on social learning theory, theory $\mathrm{x}$ and theory $\mathrm{y}$, and attachment theory to explain the effects of abusive leadership. The reason for social learning theory can be explained that people learn from leaders and then adopt those behaviors based on treatment they are met with and observing their losses they either grow or break (Nabavi, 2012). Developing countries, such as Pakistan are experiencing poor employee performance in the health sector due to many issues that have come up in the recent years.

The objectives of the research are developed to provide information regarding the leadership style, its impacts and scope. This results of which can be used to bring about changes in the working of the hospital staff in order to provide an efficient and effective workplace which would allow the employees to work without the fear of the abusive leadership and the stress can also be managed once the level of stress is analyzed with respect to organizational culture and abusive leadership style. The 
study aims to find the factors that lead to such a style of management in which abuse is used to gain and maintain control within the organization. Secondly, it is vital to understand the type of culture which allows abusive leadership to continue within the organization without many consequences. Thirdly, the research will be able to understand and evaluate the effects of abusive leadership on the performance of the employees. The most important is the linkup between abusive leadership, employee performance and organizational culture, therefore, it is crucial to understand the relationship and its extent between the three variables. Lastly, after careful evaluation of the first 4 objectives, the study will be able to provide information as to how individual behavior and coping strategies can assist in diminishing the effects of abusive leadership.

1. To assess the factors that contributes to leader's abusive style of management.

2. To assess the type of culture which cultivates abusive leadership in the organization.

3. To assess the effects of abusive leadership on employees' wellbeing and performance.

4. To assess the relationship of abusive leadership and employee performance with the element of organizational culture.

5. To assess how individuals' personality and appropriate coping strategy may jointly help in weakening the negative effects of abusive leader behaviors.

This study aims to pose 6 research questions that assist our research objectives and provide direction and understanding about the subjects in question. These research questions are able to provide a clear perspective for our research and would result in answering important questions as below:

1. Does Abusive Leadership behavior effect employees' performance?

2. Does Abusive Leadership gain more authority in a culturally controlled environment, where abusive leadership is embedded in the system?

3. Does organizational culture play an important role in promoting/obstructing abusive leadership?

4. Does Abusive Leadership/Supervision cause stress among employees?

5. Will changing the Organizational Culture about Abusive Leadership improve Employee Performance?

6. Does Abusive Leadership bring about a change in Organizational Culture those effects Employee Performance?

\title{
REVIEW OF LITERATURE
}

The review initiates with abusive leadership, which is the independent variable, which effects the employee productivity, the dependent variable through the mediating variable of organizational culture. The literature review contains papers from pioneering theories to updated and latest content available to date to ensure that the study remains valid and produces material which can be used to assist the healthcare sector in the immediate and longer run. Through breaking down each variable to understand its relationship with the rest of the framework, the study is able to provide content on how each variable has developed over the years and provided more perspective to update the framework put together in this study. The papers reviewed within are in no specific order, they go on to provide context where necessary and are able to construct a solid framework for study.

\begin{abstract}
Abusive Leadership
Wide-ranging research into the subject's literature provides the study with the framework that abusive leadership is negatively associated with employee productivity and the abusive leadership has a positive impact on the organization's culture. Abusive leadership tends to bring about harmful impact on employee empowerment which in turn causes employee to lose focus on the main tasks resulting in poor performance of the employee and a mediocre standing of the organization amidst a competitive ever changing fast paced industry (Murari, 2013). The study of Allison and Gina sheds light upon abusive leadership on young workers' and how it effects their performance and wellbeing. They portray abusive leadership as subjective in nature and therefore, analyzed it by using qualitative methods. (Starratt \& Grandy, 2010). Scholars have time and again emphasized leadership impacts and effectiveness in an organization and on a broad spectrum, a leader must have change effectiveness skills so that they can tend to isolate any negative behavior and project the best possible one to increase motivation and communication within the organization. (Gilley, Gilley, \& McMillan, 2009)
\end{abstract}




\section{Leader's Emotional Intelligence}

Emotional Intelligence has become a popular topic recently due to its substantial impact on the productivity, commitment, and well-being of the employee. Emotional Intelligence of a leader assists him in creating better interpersonal relationships at work by understanding not only own emotions and feelings but also those of the people involved. Emotional Intelligence comprises of non-cognitive abilities, skills and competencies that help the individual to cope better and make use of emotions effectively for the betterment of his position and organization. Being emotionally intelligent makes the leader more appealing, proactive, and approachable (Jabbar, et al., 2020).

Emotional Intelligence is often defined as "the ability to understand meanings of emotions and their relationships and to question them in order to make important successful decisions." A person who is emotionally intelligent is able to look at the bigger picture and understand the underlying elements, to provide a sounder judgement that involves more than just intellect. Emotional Intelligence can help understand critical situations, their meanings and then solve issues in a positive manner, whether they are domestic or work-related. A lot of information regarding emotional intelligence provides us the groundwork to deduce that an individual with a higher level of emotional intelligence has a higher chance at positive mental health, therefore, is able to work at peace and provide effective results (Pradhan \& Jena, 2018).

Daniel Goleman in his book, "Emotional Intelligence: Why it can matter more than IQ", brought about new information about why emotional intelligence is a bigger chunk of the brain that can bring about impressive results if it is enhanced or learnt. From here onwards, emotional intelligence was brought into research and theories were formulated to understand it and bring about most successful results. Goleman explains emotional intelligence under five important elements, selfawareness, self-regulation, motivation, empathy, and social skills. Most of the research of the twentieth century focused heavily on intelligence quotient, deeming it to be a critical element in finding success however, the elements highlighted by Goleman brought to light the new theory that emotional intelligence carried more weight than intelligence quotient in an individual's overall achievements (Goleman, 1995).

Research suggests that if a leader or individual at a senior position is emotionally intelligent, he/she can provide trust through their positive impact on the relationships between senior position holders and junior position holders. When choosing a leader for an organization, it is important to pick someone which higher emotional intelligence whereas, the present managers should be provided training on how to improve their emotional intelligence to ensure a high functioning organization that is able to build individuals with not only the necessary skills to work but also skills to adapt to change and to improve their lives (Xiaqi, Kun, Chongsen, \& Sufang, 2012).

The research on emotional intelligence ensures that the variable in hand is very important in comprehending why a leader chooses to be abusive or is abusive in nature and why it leads to such a circumstance where the leader is labeled abusive. Understanding the relevance of this variable in the organizational context is very vital for research as it will answer many questions.

\section{Leader's Stressors and Negative Effective State}

A leader's collaborations with the supervisory staff, higher management and board often affects their behavior and affective state with their followers or subordinates. Research points us in the direction of the trickle-down model which highlights the unequal treatment as the hierarchy goes further down from leader towards the supervisory staff. A leader's negative state can emerge from interacting with a colleague or co-worker and thereon stay with the leader for the entire day. Research suggests that when there is a high presence of leader-subordinates conflict, a rise in abusive supervision is seen. Stressors that effect the leader and impact his negative effective state can also be understood through displaced aggression theory, which is when an individual is faced with a stressful situation and is unable to show or express his feelings, those emotions and feelings are later evidently seen in his day with someone who perhaps did not deserve it and is therefore categorized as abuse. As subordinates have a lot at stake therefore, they do not talk back or take a stand for themselves which makes it easier for the leader to displace his/her aggression upon them. Leader's negative experiences, negative state, stressors, lack of interactional and procedural justice all add up to stressors that produce negative effective state in a leader (Zhang \& Bednall, 2015). 
Different stressors can affect the leaders on the daily, the stressors can be a variety of situations from their home, office, environment, and almost anything. The negative affective state can cause harm to not only the leader but also the employees he is working with. The anger, depression, frustration that the leader displays is also absorbed the employees and thereon, tends to show in their behavior as well (Bishopp, Piquero, Worrall, \& Piquero, 2018).

\section{Organizational Culture}

Organizational culture emerges from widespread themes such as social psychology, anthropology, cognitive psychology, and sociology. The depth of this term in the global era is almost immeasurable due to diversity, mixed cultures, and globalization. Culture itself revolves around ethnicity, nationalism, religion, social class, and many other factors that are now easily accessible and visible due to technology and development of countries across borders. Now the world has unlocked its potential to the functionality of working within multi-cultural groups expanding and growing faster than ever (Schein, 2010). There is a known connection between leadership and organizational culture, we sense patterning and integration in leadership as well as culture. An organizational culture becomes a part of the organization's charter without the need to explicitly announce it. Where we understand the organizational culture as the beliefs and values that become a part of the organization overtime, we also analyze how this very culture becomes a pathway for abusive leadership tending to massive decrease in employee performance. This is why it is vital to understand the relationship between organizational culture and leadership behaviors which bridges the employee performance. Culture is a very essential factor within an organization, it alone can affect the working of an employee. Once paired up with the negative consequences of abusive leadership, it brings about havoc and uncontrollable damage to the firm's productivity and success (Tsai, 2011).

Cambridge dictionary defines culture as the way of life, the beliefs, customs, and norms of a certain group at a certain point in time. It can also be defined as the interaction and behavior of the employees within the organization, the culture of an organizations highlights all the important values and aspects of that organizations (Paschal \& Ismail , 2016).

Multiple scholars have researched on dark leadership and its impact on workplace spirituality, here if we take workplace spirituality as the culture or performance, we understand the relationship between leader and employee in this context. Leaders shape the culture of the firm they are leading, their behavior is imitated and learned by the supervisors and managers working below which builds the connection of employee and employer relationship either strong or weak. It is vital to mold the organization's culture in a way that supports the employee and their wellbeing at the same, turns down dark leadership paving way for exemplary leaders (Raaj \& Gunaseelan, 2017).

The mediation effect of organizational culture has previously been studied in relation with perceived ethics and performance of SMEs. The findings of this paper concluded with significant results on the mediation of organizational culture with perceived ethics and performance of SME's, as well as provided practitioners and policy makers the idea to endorse social responsibility while designing strategic plans to materialize and comprehend superior performance. Relationship between organizational culture and performance was highlighted, organizational culture has the ability to effect organizational outcomes. Schein (1992) model is also mentioned in this paper explaining how organizational culture has different stages that have an effect on the organizational performance. It is verified that the constructive culture of an organization has an impact on the performance factor of the organization leading it towards success. There is an equivalent linking between organizational culture, leadership efficacy and organizational performance (Gorondutse \& Hilman, 2016).

Previous research provides context about the direct relationship of abusive leadership and its effects on employee performance however, this approach hinders the understanding of the real predictors of organizational commitment. There is literature that supports in determining the mediating effect of organizational culture on the relationship between leadership and organizational commitment. As the employees of an organization share the same values and assumptions creating their identity at work, through this process their organizational commitment is enhanced. Organizational commitment is the by-product of organizational culture. The anecdotal theoretical stance suggests that organizational culture is derived from leadership, leaders change the organizational culture by aligning it with the organization's vision and prepare it for successful organizational changes (Abdullah, Shamsuddin, \& Wahab, 2015). 


\section{Employee Performance}

Employee performance can be measured by evaluating the competence of an employee to accomplish their tasks in accordance with the preset standard of completeness, precision, cost and speed. The success of an organization lies heavily on the employee productivity. The employees of an organization are able to take the organization to new heights of success or bury it in financial debts due to the stress and frustration of the staff's inability to work in a distressed environment. Human resource is the key to succeeding in any task, the employee is a major asset of the organization and should be looked after well. If the employee is productive, the organization is bound to be profitable due to the efforts of the employees however, if the same employees are not taken care of, the productivity can go down the drain leading to a severe crash in the system. According to research, Uganda's Health sector also performs better when training is provided to employees along with employee engagement activities which allows them to work more efficiently (Sendawula, Kimuli, Bananuka, \& Muganga, 2018).

Literature supports the claim that abusive leadership obstructs the functionality of an employee. It also suggests that positive interactions between the leader and employee assist in an increased productivity at work which eventually directs the organization on the path to succeed in the longer run. The victims of abusive leadership tend to lose interest in work as they are demotivated by the pressure and stress which is tossed on them every now and then. This results in less self-interest to work by the employees which undermines their working ability and makes them self-doubt their work resulting in high turnover intention and decreased productivity on a large scale (Hussain, Abbas, Gulzar, Jibril, \& Hussain, 2020).

\section{Theoretical Framework}

Figure 1 - Conceptual Model examined in current study.

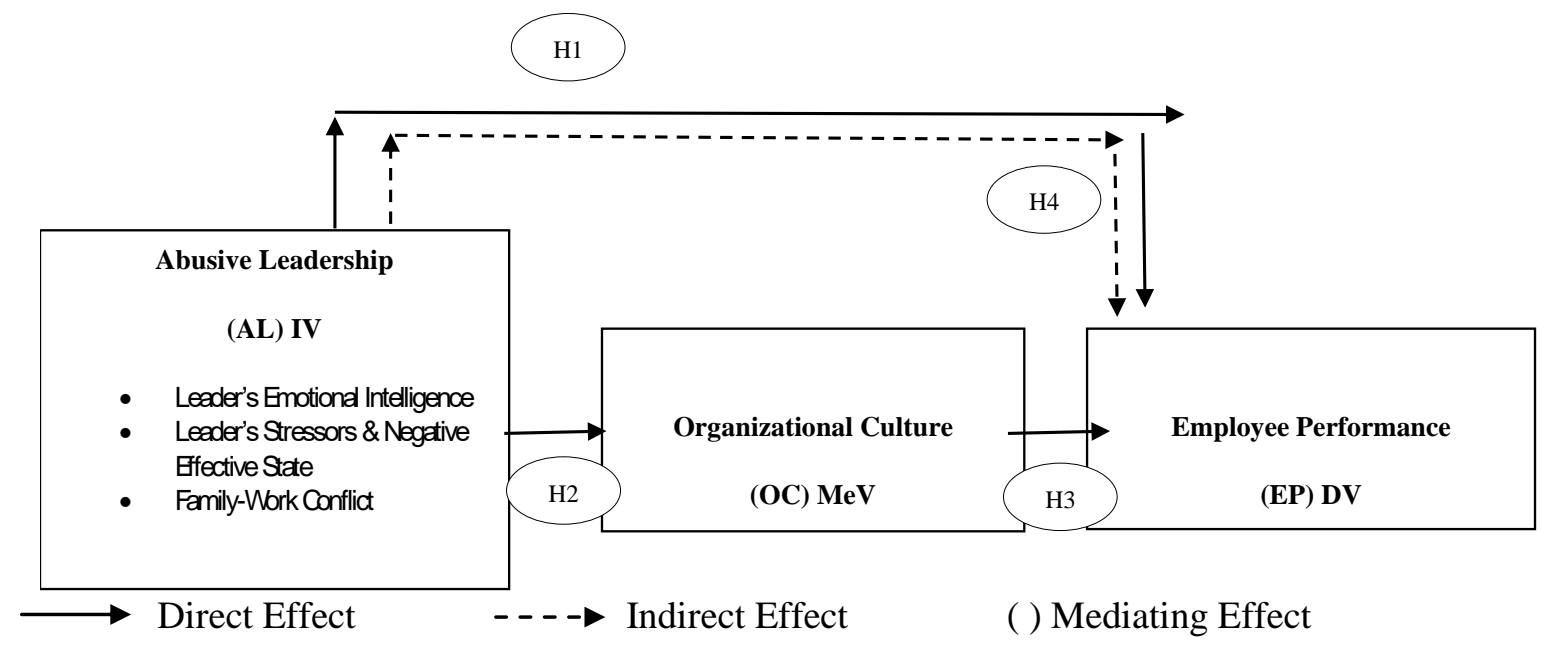

\section{Antecedents of Abusive Leadership}

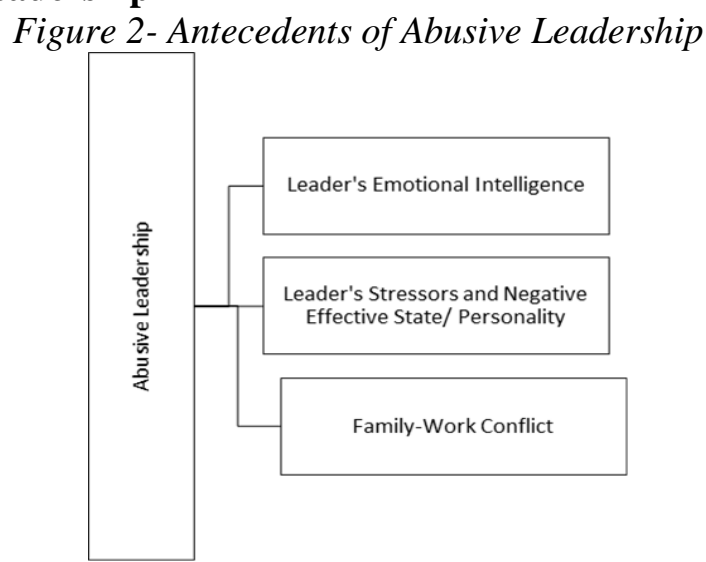

Source: (Park, 2012), (Zhang \& Bednall, 2015) 
The above mentioned three antecedents were chosen from a mix of two research papers, one by Joon Hyung Park's dissertation on antecedents and outcomes of abusive supervision and the other one, Antecedents of Abusive Supervision: A Meta-analytic Review by Yucheng Zhang \& Timothy C. Bednall.

\section{Hypotheses}

In light of the research objectives and proposed framework, the following hypothesis were developed for the study of the variables:

H1: There is a relationship between Abusive Leadership and Employee Performance

There is a negative relationship between abusive leadership and employee performance; increase in abusive leadership decreases the employee performance whereas, the decrease in abusive leadership increases the employee performance.

$\mathrm{H} 2$ : There is a relationship between Abusive Leadership and Organizational Culture

Organizational culture plays a vital role in any organization, where there is abusive leadership, there is an effect on organizational culture. There is a positive relationship between abusive leadership and organizational culture; more the abusive leadership, more toxic the organizational culture is made.

H3: There is relationship between Organizational Culture and Employee Performance

Organizational culture directly effects the employee performance. If the organizational culture is toxic due to abusive leadership, the employee performance will be low however, if the organizational culture is healthy due to good leadership, the employee performance will be superior.

H4: Organizational Culture acts as a mediator between Abusive Leadership and Employee Performance

This study predicts that there is a relationship between abusive leadership and employee performance as well as there is a mediating effect of organizational culture between the abusive leadership and employee performance.

\section{RESEARCH METHODOLOGY}

The work was carried out to collect primary data from the hospitals through questionnaires from the frontend, paramedical staff, doctors, and administrators in the hospitals, this will also aid in pinpointing where the abuse lies the most. Some of the questionnaires were sent by hand while some were emailed through to maximize timely responses. The questionnaires contained brief background information, but also provide the employees confidentiality through not asking for their names and personal information. The information required is strictly for research and that will be conveyed to their respondents as well.

\section{Reliability and Validity of the Instruments}

The Cronbach's Alpha values depict the reliability of each of the variable mentioned above. Cronbach's alpha is mostly used to measure the internal consistency or in other words, reliability of variables. This statistical analysis is often used when the questionnaire comprises of Likert-scale questions. There is a high level of internal consistency which can be noted by the indication of the Cronbach's alpha values at $.768, .712, .867, .885$, and .753 , against the $10,5,10$ and 8 items for leadership, employee performance, stress, and organizational culture, respectively. Below is the reliability table extracted from SPSS analysis.

This above statement established the reliability and validity of the variables under study providing an accurate platform to build the research upon. This research will now be able to contribute with other relevant research to provide literature and context.

Table No. 1 - Reliability of the variables

\begin{tabular}{lll}
\hline Variables & Items & Reliability \\
\hline Leadership & 10 & 0.768 \\
Employee Performance & 05 & 0.712 \\
Stress & 10 & 0.867 \\
Organizational Culture & 08 & 0.885
\end{tabular}




\section{RESULTS AND DATA ANALYSIS}

A total of 350 questionnaires were floated from the first set for the medical staff, 35 supervisory staff questionnaires were also sent out to the 6 hospitals. These questionnaires were handed to the admin branch of the hospitals and were requested to be returned in a week's time. In some hospitals, due to time constraint, the questionnaires were handed to the hospital staff directly in order to expedite the data collection process. A reminder was sent out the hospital staff around mid-week to ensure the survey would be complete on time. The hospitals were provided with the researchers details to reach out upon completion of the data collection, some hospitals provided the filled-out questionnaires before time and other provided around the deadline. The questionnaires were picked up from the admin branch of the hospitals or the concerned hospital staff and were then carefully marked with the names of the hospitals on the back side of each questionnaire to ensure they are properly categorized for data analysis.

\section{Descriptive Statistics}

The descriptive analysis of our data within the study is composed of measures of central tendency, which encompasses mean, standard deviation, variance, skewness, and kurtosis. The table below shows mean, standard deviation, variance, skewness, and kurtosis of the variables' leadership, employee performance, stress, and organizational culture, respectively. Through descriptive statistics, the researcher is able to quantitatively represent the data collected while application of thorough analysis on the content.

The application of descriptive statistics under this study is able to provide brief descriptive coefficients which were able to summarize the collected dataset. These statistic encompass a variety of measures such as mean, median, mode (central tendency: provides content regarding the center of a dataset), standard deviation, variance, maximum and minimum values, skewness and kurtosis (measure of variability: provide content regarding the spread and dispersion present in the dataset) under the central tendency and variability analysis.

\section{Data Normality}

\section{Table No. 2 - Data Normality Table}

\begin{tabular}{|c|c|c|c|c|c|c|c|c|}
\hline \multicolumn{9}{|c|}{ Descriptive Statistics } \\
\hline & $\mathrm{N}$ & Mean & Std. & Varianc & Skewnes & & Kurtosis & \\
\hline & Statistic & Statistic & Statistic & Statistic & Statistic & $\begin{array}{l}\text { Std. } \\
\text { Error }\end{array}$ & Statistic & $\begin{array}{l}\text { Std. } \\
\text { Error }\end{array}$ \\
\hline Leadership & 300 & 2.8513 & .72557 & .526 & .062 & .141 & -.613 & .281 \\
\hline $\begin{array}{l}\text { Employee } \\
\text { Performance }\end{array}$ & 300 & 2.9953 & .57609 & .332 & .199 & .141 & .332 & .281 \\
\hline Stress & 300 & 3.0213 & .82940 & .688 & -.294 & .141 & -.458 & .281 \\
\hline $\begin{array}{l}\text { Organizational } \\
\text { Culture }\end{array}$ & 300 & 3.3725 & .80029 & .640 & -.446 & .141 & -.152 & .281 \\
\hline
\end{tabular}

The interpretation of the tables above indicates that means of the variables lie around the value 3 which is the mid value of the 5-point Likert scale used for data collection, indicating the overall neutrality of the values selected by the participants. Organizational culture (C) has the highest mean value of (3.37), followed by Stress (S) which is (3.02), after which we have Employee Performance (2.99) and lastly, Leadership (2.85). The value of standard deviation ranges from .57 till .82 which indicates a rather narrow distribution around the mean of the data collected.

"The SD is a measure of how spread-out values are from its mean value. Its symbol is $\sigma$ (the Greek letter sigma) or s. It is called SD because we have taken a standard value (mean) to measures the dispersion. The variance $\left(\mathrm{s}^{2}\right)$ is defined as the average of the squared difference from the mean. It is equal to the square of the SD (s)." (Gupta, Singh, Pandey, \& Mishra, 2019) The standard deviation of the variables lies between the range of $(.57-.82)$, the variance falls within the range of $(.33-.68)$. The spread of the value from the mean is narrow. The variance is the squared difference from the mean, which for our variables lie between (.33-.68). 
The review of the means also sheds light upon how abusive supervision impacts the dependent variables such as stress and mediating variable of organizational culture. The Skewness of the variables is well within range (+1 to -1$)$, as well as the Kurtosis which falls within the same range. "A distribution is called approximate normal if skewness or kurtosis (excess) of the data are between - 1 and + 1." (Gupta, Singh, Pandey, \& Mishra, 2019), which is evident within the table shared above of all the variables.

\section{Demographics Analysis}

This demographic data is able to provide relevant details regarding trends, as well as it is considered a powerful tool when predicting behavior and demands to understand choices, past behavior, and characteristics.

\section{Table No. 3 Demographic Questions}

\begin{tabular}{ll} 
Sr.\# & Demographic \\
\hline 1 & Age \\
2 & Gender \\
3 & Marital Status \\
4 & Qualification \\
5 & Years of Experience with this hospital \\
6 & Designation \\
\hline
\end{tabular}

The table below mentioned the demographics variables that were viewed in the study within the parameters of the questionnaire which was distributed among supervisors of the selected private and public hospitals.

\section{Age}

Table No. 4 - Demographic Details regarding Age Brackets of Respondents

\begin{tabular}{lll} 
Age & Frequency & Percent \\
\hline $20-30$ & 213 & 71.0 \\
$31-40$ & 68 & 22.7 \\
$41-50$ & 16 & 5.3 \\
$51-60$ & 3 & 1.0 \\
Total & 300 & 100.0 \\
\hline
\end{tabular}

From the table shared above, it is evident that most of the data collection was made from a younger age bracket, 20-30 years old, mostly due to their availability. The seconded highest collection was made from the age bracket 31-40 years old, after which we see 16 collections were made from 41-50 years old and 3 collections were made from 51-60 years old. A total of 300 forms were filled accurately. The review of above demographic data helps in explaining that majority of the data was from participants of the early age group (20-30). The data was collected from within Islamabad and Rawalpindi hospitals.

\section{Gender}

\section{Table No. 5 Demographic Details regarding Gender of Respondents}

$$
\text { Gender Prequency Percent }
$$

\begin{tabular}{llll}
\hline \multirow{3}{*}{ Valid } & Male & 167 & 55.7 \\
& Female & 133 & 44.3 \\
& Total & 300 & 100.0 \\
\hline
\end{tabular}

From the above table, we can conclude that a balanced approach was formed to circulate the questionnaires in a way that represented both the genders with a $56-44 \%$ distribution. $56 \%$ of the questionnaires were filled by men whereas, $44 \%$ of the questionnaires were filled by women. In terms of gender, it is evident that the male population accounts for about $55.7 \%$ whereas, the female population account for $44.3 \%$. The geographical coverage of this population was restricted within Islamabad and Rawalpindi however, the distribution between the gender is towards a good balance. 


\section{Marital Status}

Table No. 6 - Demographic Details regarding Marital Status of Respondents

\begin{tabular}{llll} 
Marital Status & & Frequency & Percent \\
\hline \multirow{3}{*}{ Valid } & Single & 182 & 60.7 \\
& Married & 118 & 39.3 \\
& Total & 300 & 100.0
\end{tabular}

The above table confirms that $61 \%$ of our responses came from single people whereas, $39 \%$ of our responses came from married people. Through the first demographic question, we can understand that the population of single participants is more due the high participation of individuals from the age group of 20-30 years.

\section{Qualification}

Table No. 7 - Demographic Details regarding Qualification of Respondents Qualification Frequency

Percent

\begin{tabular}{lrr}
\hline Matric & 7 & 2.3 \\
Intermediate & 15 & 5.0 \\
Bachelors & 50 & 16.7 \\
Masters & 39 & 13.0 \\
MBBS & 128 & 42.7 \\
MBBS/FCPS & 24 & 8.0 \\
BDS & 4 & 1.3 \\
General Nursing & 33 & 11.0 \\
Total & 300 & 100.0
\end{tabular}

From the above table, we can conclude that a mixed set of qualified respondents were part of the sample, representing a real-time hospital staff. The minority of the hospital staff and helpers including some of the nurses had Matriculation degrees, which built $2.3 \%$ of the demographic. The Intermediate qualified respondents were $5 \%$ of the population. The Bachelor's degree holders contributed to $17 \%$ of the population, along with an additional $1 \%$ for the BDS qualified doctors. The Master's degree holders contributed to $13 \%$ of the sample, along with additional $43 \%$ for the MBBS, and additional $8 \%$ for the MBBS/FPCS degree holders. The general nursing diploma holders built up $11 \%$ of the total sample. The geographical coverage of this population was restricted within Islamabad and Rawalpindi public and private hospitals. The majority of the questionnaires as per the table and chart above, were attempted by MBBS qualified individuals, which represented our dataset as per the plan.

\section{Years of Experience with this hospital}

Table No. 8 - Years of Experience

\begin{tabular}{cccc}
\multicolumn{2}{c}{ Years } & Frequency & Percent \\
\hline & Less than & 56 & 18.7 \\
& $1-3$ & 55 & 18.3 \\
$4-6$ & 61 & 20.3 \\
Valid & $7-9$ & 61 & 20.3 \\
& $10-12$ & 24 & 8.0 \\
$13-15$ & 19 & 6.3 \\
$16-20$ & 13 & 4.3 \\
& $21-24$ & 11 & 3.7 \\
& Total & 300 & 100.0 \\
\hline
\end{tabular}

The table above show that the sample set for the research was mainly well adjusted within the hospitals portraying that the respondents with less than 1 year of experience were about $19 \%$ of the total sample size, respondents with 1-3 years of experience made up 18\% of the sample size, respondents with 4-6 years of experience were 20\%, 7-9 years of experience were at 20\%, 10-12 years 
of experience were at 8\%, 13-16 years of experience were at 6\%, 16-20 years of experience were at $4 \%$ and 21-24 years of experience were at $4 \%$ from the total sample size under study. Apart from the overall percentages of the sample size, this categorization is able to provide a diverse set of employees with variety of experience within the hospitals.

\section{Designation}

The designation of the employees was asked for reference however, it is not measured within the descriptive analysis as the categories of the designation were wide-spread and detailed due to the open-ended question therefore, adding each and every category specifically would have been very time-consuming and unnecessary effort. Below are some of the major designations mentioned in the survey for perspective purposes only.

\section{Correlation Analysis}

The degree of association is measured by a correlation coefficient, which is denoted by $r$. It is often referred to as, Pearson's correlation coefficient. Pearson's correlation was named after the person Pearson himself. It is a measure of linear association. If ever there is a curved line necessary to express the relationship between the variables, other types of measures of the correlation are used. Pearson's correlation coefficient is the test that is used to measure statistical relationship between variables such as the ones mentioned below:

\section{Pearson's Correlation Table}

Table No. 9 - Pearson's Correlation Table

\begin{tabular}{cccccc} 
& \multicolumn{1}{c}{$\begin{array}{c}\text { Correlations } \\
\text { Abusive } \\
\text { Leadership }\end{array}$} & EP & S & C \\
\hline $\begin{array}{c}\text { Abusive } \\
\text { Leadership }\end{array}$ & Pearson Correlation & 1 & & $* *$ \\
$\begin{array}{c}\text { Employee } \\
\text { Performance }\end{array}$ & Pearson Correlation & .959 & 1 &. & $* * *$ \\
Stress & Pearson Correlation & $.530^{* *}$ & .001 & 1 & $* * *$ \\
$\begin{array}{c}\text { Organization } \\
\text { al Culture }\end{array}$ & Pearson Correlation & $-.249^{* *}$ & $.306^{* *}$ & $-.472^{* *}$ & 1 \\
\cline { 2 - 6 } & & & &
\end{tabular}

Abusive Leadership's correlation with employee performance is (.959), Abusive Leadership's correlation with stress is (.530), Abusive Leadership's correlation with organizational culture is (.249). The correlation of Employee performance with leadership is (.003), with stress is (.001), with organizational culture is (.306). The correlation of Stress with leadership is (.530), with employee performance is (.001), with organizational culture is (-.472). The correlation of organizational culture with abusive leadership is (.-249), with employee performance (.306), with stress is (.-472). Leadership when abusive produces culture with a negative correlation, this negative culture effects the employee performance.

\section{Regression Analysis}

Regression is often used in statistical analysis to understand the relationship between independent and dependent variables. It is able to assess the strengths of the variable relationship. There are usually three kinds of regression analysis performed in research and other domains, linear regression, multilinear regression, and non-linear regression. Within this study, there is application of linear-regression analysis on the variables in the framework, which assisted in building the $1^{\text {st }}$ questionnaire.

In this section, we have analyzed how the dependent variable changes with respect to the independent variable, as in the case with abusive leadership as the independent variable and employee performance as the dependent variable. 
Table No. 10 - Regression Analysis - Model Summary

\begin{tabular}{|c|c|c|c|c|}
\hline \multicolumn{5}{|c|}{ Model Summary } \\
\hline Model & $\mathrm{R}$ & R Square & Adjusted R Square & $\begin{array}{l}\text { Std. Error of the } \\
\text { Estimate }\end{array}$ \\
\hline 1 & $.003^{\mathrm{a}}$ & .000 & -.007 & .57803 \\
\hline
\end{tabular}

a. Predictors: (Constant), S, Leadership

Through regression analysis of the study, we can conclude that there is a negative relationship of the model, if there is $1 \%$ change that happens in the independent variable (Abusive Leadership), it will bring $7 \%$ change in dependent variable (Employee performance). $\mathrm{R}$ square value being stated at .000 means that our model is significant. As per the table above, if there is an increase in abusive leadership, there is a significant decrease in employee performance.

The regression analysis is able to impact the overall outcome of the relationship. It is able to assist in which variable is more important in relationship with the other. This analysis is often use in various types of studies in multiple domains around the world to analyze the effects of independent variable over the dependent variable.

Below is another table that describes regression values in a more in-depth form. The table covers the model, unstandardized coefficients, standardized coefficients, $\mathrm{T}$ and significance.

Table No. 11 Regression Coefficients Table

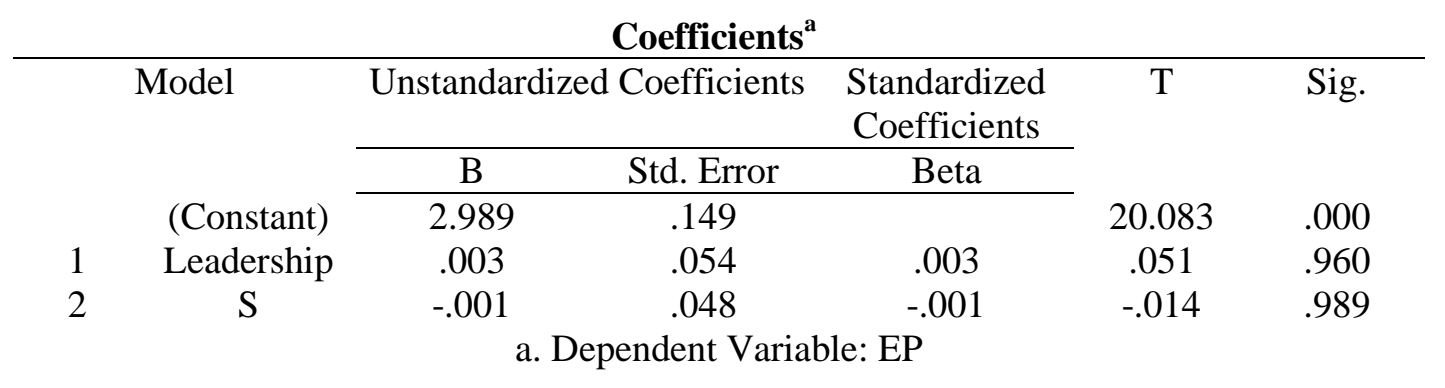

\section{Mediation}

A statistical method used to understand causal relationship by an antecedent variable which causes a mediating variable that thereon causes a dependent variable, this relationship is called a mediating relationship. For a mediating relationship, a mediating analysis is required. A mediating variable often transmits the effect of an independent variable onto the dependent variable. The mediation processes are explained in terms of intermediate variables among an independent variable IV and a dependent variable $\mathrm{DV}$, with at least three variables required in total: $\mathrm{A}, \mathrm{B}$, and $\mathrm{C}$, where $\mathrm{A}$ is the independent variable; Abusive Leadership (IV), $\mathrm{C}$ is the dependent variable (Employee Performance) (DV), and $\mathrm{B}$ is considered as the mediator variable that is in theory able to transmit the causal effect of $\mathrm{A}$ to $\mathrm{C}$.

\section{Coefficients}

Coefficients analysis is able to provide an approach to predict values. It is helpful in providing data regarding significance of relationships. An increase in a predictor variable and a simultaneous increase in a response variable is able to build a positive relationship sign. The first part of the table, ' $\mathrm{B}$ ', is also known as the regression equation, the next column represents standard of error also known to calculate the margin of error. The standardized coefficients are often the same as the original B. The Beta coefficient is able to define the rate of variation. A positive beta interpretation would result in equal change across the variables, meaning 1 unit change in predictor variable would result in 1 unit change in response variable. The $t$ scores are B divided by standard error. The last value is the significance value, often known as the $\mathrm{P}$ value. If the $\mathrm{P}$ value is less than .05 , the hypothesis is rejected. 
Table No. 12- Coefficient Table for Abusive Leadership \& Organizational Culture

\begin{tabular}{|c|c|c|c|c|c|c|}
\hline \multicolumn{7}{|c|}{ Coefficients $^{\mathrm{a}}$} \\
\hline \multirow{2}{*}{\multicolumn{2}{|c|}{ Model }} & Unstandar & Coefficients & $\begin{array}{c}\text { Standardized } \\
\text { Coefficients }\end{array}$ & $\mathrm{t}$ & Sig. \\
\hline & & B & Std. Error & Beta & & \\
\hline \multirow{3}{*}{1} & (Constant) & 2.989 & .149 & & 20.083 & .000 \\
\hline & Leadership & .003 & .054 & .003 & .051 & .960 \\
\hline & $\mathrm{S}$ & -.001 & .048 & -.001 & -.014 & .989 \\
\hline
\end{tabular}

a. Dependent Variable: EP

The table above explains that with a unit increase in the first variable, there would be a -.001 unit decrease in the second variable. $T$ test score provides the detail regarding the significance of beta from zero. If there is insignificant $t$ value, it would mean that the variable is unable to predict the desired outcome. The relationship between the independent and dependent variable is present in the table above and the values are able to predict the outcomes whether positive or negative. Model 1 has coefficients that are significant and have positive relationships throughout the table. Where there is 1 unit increase in abusive leadership, there is .003 unit increase in employee performance, where there is 1 unit increase in abusive leadership,

\section{Hypothesis Testing}

The framework of the study revolved around 3 main variables, Abusive leadership; the independent variable (IV), Organizational culture; the mediating variable (MeV), and Employee Performance; the dependent variable (DV).

Multiple analyses were applied to understand the relationship between the variables, to understand the correlation between the data and proposed hypothesis, Pearson's correlation analysis was applied. A through descriptive statistical analysis was applied on the variables along with other analysis to understand the mediation effect on the variables.

Below are the results of the tests which have led to the conclusive results of the hypothesis mentioned below as accepted/rejected.

Table No. 13: Hypotheses Results

Sr\# Hypothesis

1. $\mathrm{H} 1$ : There is a relationship between Abusive Leadership and Employee Performance

2. H2: There is a relationship between Abusive Leadership and Organizational Culture

Research Questions

Result
(Supported/Not
Supported)

Research Question: 1. Does Abusive

Supported

Leadership behavior effect employees'

performance?

Research Question 2. Does Abusive

Supported

Leadership gain more authority in a culturally

controlled environment, where abusive

leadership is embedded in the system?

3. H3: There is a relationship between Organizational Culture and Employee

Research Question 3. Does organizational culture play an important role in

Supported

promoting/obstructing abusive leadership?

Performance

4. H4: Organizational Culture acts as a mediator between Abusive Leadership and Employee Performance

Research Question 5. Will changing the Organizational Culture about Abusive Leadership improve Employee Performance? 6.Does Abusive Leadership bring about a change in Organizational Culture that effects Employee Performance? 


\section{CONCLUSION}

Conclusively, it can be said that through guidance of the objectives for research, research questions, literature review, and hypothesis development, a theoretical framework was created to ensure the elements and essence of the research and covered. A sample of 350 employees from the healthcare sector were selected for this research for the purpose of gaining authentic results from the area including public and private sector hospitals; another sample of population of 35 from the supervisory staff of the hospitals was selected for the study. After the surveys were conducted, a thorough analysis was carried out on SPSS which further refined our study and confirmed the hypothesis and research questions. The hypothesis results indicated that abusive leadership lies within our private and public hospitals, it effects the employee performance, and the overall culture of the organization plays a vital role in promoting this kind of leadership. The results conclude that there is a negative relationship between abusive leadership and employee performance. There is a positive relationship between weak organizational culture and abusive leadership. There is a significant relationship between the organizational culture and abusive leadership. There is a positive relationship between abusive leadership and stress, more the abusive leadership, more the stress in the employees. The findings of this study bring about suggestions and recommendations for the healthcare sector as well as any organization suffering with abusive leadership. The study is able to enrich literature by primarily introducing the element of abusive leadership, organizational culture and employee performance under an umbrella and explaining its relationship with-in healthcare sectors of Pakistan. Through this study, we are not only able to identify where abusive leadership lies but also understand how it effects the ability of the employees. Through establishing this work, we are able to provide real-time data and real-time solutions for the healthcare sector. Through addressing this gap in our literature, organizations, and overall firms, we are able to provide essential help to the organizations, particularly the healthcare sector around the world. This study brings about the aspects of abusive leadership as well as the effects of such a leadership. It is able to build a deeper understanding of the concept and its affects in real time.

\section{RECOMMENDATIONS}

The effects of abusive leadership are widespread and mostly negative as explained in this study, this type of leadership results in a decrease in job satisfaction, and an evident decrease in employee performance. The decrease in employee performance leads to an increase in employee grievances, increase in turnover and a decrease in productivity. These abusive effects bring about a change in the overall health of the employee as well as the mental health of the employee. It is so important to address this kind of leadership within the hospitals where work is performed around the clock and a single error can lead to loss of an important life. This statement and the previous literature led to building the relationship of abusive leadership with employee performance and the organizational culture role that bridges the independent and dependent variable effects. The findings of the study are able to provide both practical application and implications along with extension to the already present western theories of abusive supervision and workplace deviance. The recommendations of the study include hints for reducing both psychological and financial costs of such type of deviant behavior.

Below are some of the recommendations that have been put fourth after the analysis and discussion of the study:

- Abusive Leadership must be recognized, and awareness must be brought about the firms. The firms must be clear to term abusive leadership with a zero-tolerance policy.

- Employees reporting this type of behavior must be protected; the whistleblowers must not be named; their privacy and details must remain confidential. Feedback should be encouraged. The study emphasizes the usefulness of integrating negative behaviors, such as abusive supervision, into a 360-degree feedback and to carefully disentangle interactions both for the benefit of the leader and the employee reporting to him/her as well as the entire organization.

- Organization must conduct surveys every six months to check employees' wellbeing and productivity; one way or the other the underlying elements will provide details about abusive supervision, if any. 
- The organizations must create healthy assistance programs to ensure their employees can express themselves freely and have a channel to address their concerns to.

- The organizations should try to endorse social responsibility within the firms, policy makers leaders and management employees should endorse this social responsibility, this would eventually become part of the culture and mitigate the effects of abusive leadership.

- Human Resource should play an active role in observing management and employee behaviors by detecting signs of distress, absenteeism, and other alarming factors in the employees. The role of ethical leadership should be encouraged and practiced within the firms to ensure a fair and just system.

\section{REFERENCES}

Abdullah, N. H., Shamsuddin, A., \& Wahab, E. (2015). Does organizational culture mediate the relationship between transformational leadership and organizational commitment? International Journal of Organizational Leadership, 4, 18-32.

Bashir, U., \& Ismail Ramay, M. (2010). Impact of stress on employees job performance: A study on banking sector of Pakistan. Bashir, U., \& Ramay, MI (2010).

Bhat, R., \& Jain, N. (2006). Analysis of public and private healthcare expenditures. Economic and Political weekly, 57-68.

Gunaseelan, R. (2018). Dark leadership and its impact on work place spirituality: an empirical study. PURUSHARTHA-A journal of Management, Ethics and Spirituality, 10(1), 32-42.

Long, C. S., Thean, L. Y., Ismail, W. K. W., \& Jusoh, A. (2012). Leadership styles and employees' turnover intention: Exploratory study of academic staff in a Malaysian College. World Applied Sciences Journal, 19(4), 575-581.

Slattery, J. P., \& Rajan Selvarajan, T. T. (2005). Antecedents to temporary employee's turnover intention. Journal of Leadership \& Organizational Studies, 12(1), 53-66.

Specchia, M. L., Cozzolino, M. R., Carini, E., Di Pilla, A., Galletti, C., Ricciardi, W., \& Damiani, G. (2021). Leadership Styles and Nurses' Job Satisfaction. Results of a Systematic Review. International Journal of Environmental Research and Public Health, 18(4), 1552.

Starratt, A., \& Grandy, G. (2010). Young workers' experiences of abusive leadership. Leadership \& organization development journal.

Stempel, C. R., \& Rigotti, T. (2018). Leaders' Gender, Perceived Abusive Supervision and Health. Frontiers in psychology, 9, 2427.

Surienty, L., Ramayah, T., Lo, M. C., \& Tarmizi, A. N. (2014). Quality of work life and turnover intention: a partial least square (PLS) approach. Social indicators research, 119(1), 405-420.

Tepper, B. J. (2000). Consequences of abusive supervision. Academy of management journal, 43(2), 178-190.

Tsai, Y. (2011). Relationship between organizational culture, leadership behavior and job satisfaction. BMC health services research, 11(1), 1-9.

Tynkkynen, L. K., \& Vrangbæk, K. (2018). Comparing public and private providers: a scoping review of hospital services in Europe. BMC health services research, 18(1), 1-14.

Tsai, W. H., Shaw, M. J., Fan, Y. W., Liu, J. Y., Lee, K. C., \& Chen, H. C. (2011). An empirical investigation of the impacts of internal/external facilitators on the project success of ERP: A structural equation model. Decision Support Systems, 50(2), 480-490.

Wallace, E., \& De Chernatony, L. (2009). Service employee performance: its components and antecedents. Journal of Relationship Marketing, 8(2), 82-102.

Wulani, F., Purwanto, B. M., \& Hani, H. (2014). Abusive supervision scale development in Indonesia. Gadjah Mada International Journal of Business, 16(1), 55-68.

Xiaqi, D., Kun, T., Chongsen, Y., \& Sufang, G. (2012). Abusive supervision and LMX: Leaders' emotional intelligence as antecedent variable and trust as consequence variable. Chinese Management Studies.

Zaccaro, S. J. (2002). Organizational leadership and social intelligence. In Kravis-de Roulet Leadership Conference, 9th, Apr, 1999, Claremont McKenna Coll, Claremont, CA, US. Lawrence Erlbaum Associates Publishers.

Zhang, Y., \& Bednall, T. C. (2016). Antecedents of abusive supervision: A meta-analytic review. Journal of Business Ethics, 139(3), 455-471. 